\title{
"Pura, dura e segura": a vida das pensionistas do Colégio São José de Pelotas
}

\author{
Eduardo Arriada \\ Rita de Cássia Grecco dos Santos
}

\begin{abstract}
Resumo
O presente texto refere-se a uma análise da vida das pensionistas do Colégio São José, uma instituição de ensino quase centenária da cidade de Pelotas/RS. Jovens pensionistas que eram formadas no lema: "pura, dura e segura". Assim, ao caracterizarmos o funcionamento do internato, das práticas pedagógicas vigentes durante seu funcionamento, o cotidiano escolar, as disciplinas-saber e os manuais escolares utilizados, ensejamos compreender como era exercido o controle e disciplinamento destas jovens. Sendo que, para além das disciplinas-saber, aprendiam também boas maneiras, obediência, postura, canto e desenho. Portanto, para realizarmos a referida análise recorremos aos trabalhos de Foucault (1984), Forquin (1992) e Chervel (1998), entre outros, subsídios fundamentais para estudarmos como a cultura escolar, para além das relações de poder, plasmava esse modelo de educação.
\end{abstract}

Palavras-chave: Internato, Instituições Escolares, História da Educação.

\section{"Pure, hard and safe": the boarders' life at Sao Jose School in Pelotas}

\begin{abstract}
The present text makes reference to an analysis of the boarders' life at Sao Jose School, a nearly centenary teaching institution in Pelotas city - Rio Grande do Sul/Brazil. Young boarders who were shaped by the motto: "Pure, Hard and Safe". This way, when we distinguish the boarding school operational system, the current pedagogical practices at that time, the school routine, the mandatory subjects and the school manuals employed, we take this opportunity to understand how the control and discipline of these young girls were carried out. Moreover, besides the mandatory subjects, they also had to learn good manners, obedience, posture, singing and drawing. Therefore, in order to achieve this present analysis we have resorted to works from Foucault (1984), Forquin (1992) and Chervel (1998) amongst other fundamental support to study how this school culture, further away than any relations of power, used to structure this model of education.
\end{abstract}

Key Words: Boarding School, School Institutions, History of Education. 
As primeiras décadas do século XX em Pelotas podem ser caracterizadas como um momento de expansão e crescimento do ensino particular, uma vez que as próprias autoridades públicas incentivavam essa política como podemos verificar pelo discurso do Intendente Municipal José Barbosa Gonçalves:

Em vez do ensino oficial, que já fez sua época de estreiteza dogmática, com suas pragmáticas e peãs, com concursos de aparato e a efetividade que, muitas vezes, só permeia um esforço de ocasião ou uma felicidade do acaso, e pode matar, na sua dissecante atmosfera, o gérmen do estímulo, que deve ser, na livre concorrência, guia de ação constante, estabeleça-se a plena liberdade, que leva o espírito desimpedido a agir, autônomo, em busca de maior desenvolvimento para firmeza de uma situação em que a sua utilidade se defina (RELATÓRIO, 1910, p. 16).

Do mesmo modo, o estabelecimento do Bispado em Pelotas em 1911, na figura de Francisco de Campos Barreto, alavancou o papel interventor da Igreja Católica em diversas atividades, entre elas a educacional. "Não se ativou na diocese, somente a edificação de igrejas para a pregação do evangelho, pensou-se também na construção de colégios para o ensino das ciências" (PRIMEIRO LUSTRO, 1917, p. 143).

Assim, o estabelecimento de um grande educandário feminino há muito esperado, logo se torna realidade, pois a Igreja pregava a importância de uma formação católica para as moças, de acordo com o segundo Bispo de Pelotas, Joaquim Ferreira de Mello: "[...] formar em círculos especiais a mocidade feminina, dando-lhe a inteligência da sua missão educadora na sociedade, e orientandolhe a vida para as virtudes tradicionais da família brasileira [...]" (MELLO, 1935, p. 205).

Chegando a São Paulo em 1859, as Irmãs de São José de Chamberry ampliam sua ação em
1895, quando por influência do Bispo Dom Antônio Joaquim de Melo, estabelecem-se em Curitiba e três anos mais tarde, em 1898, instalavam-se também em terras gaúchas a convite de Dom Claúdio José Ponce de Leão, Bispo de Porto Alegre, sendo que somente em 1910, finalmente chegam à cidade de Pelotas (O SÃO JOSÉ, 1960; MANOEL, 1996).

A criação e o desenvolvimento das diversas Congregações das Irmãs de São José deram-se dentro de um contexto em que a Igreja Católica buscava reorganizar-se_frente ao crescimento das Igrejas protestantes. Embora, por um lado, tenha tratado de melhorar a formação dos padres com o estabelecimento de diversos seminários, as atividades que implicavam no "cuidar": assistência a órfãos e doentes, orientação profissional e moral, acabaram em grande parte nas mãos das religiosas. De acordo com Pizani:

O espaço conquistado pelas congregações femininas deveu-se aos avanços em relação às idéias da vida religiosa que resultaram no rompimento com a exigência da clausura, abrindo-se caminhos para a atuação da mulher na área social, no cuidado de doentes e idosas, na educação de crianças e jovens, no atendimento aos excluídos [...]. Todo esse cuidar não acontecia apenas no plano físico e social, mas se complementava com o cuidado espiritual. (2005: 74)

Entrelaçando uma formação humanística, onde entre as disciplinas-saber o francês pontuava, estudavam ainda doutrina cristã, música, ciências, história e geografia, mas também, economia doméstica, trabalhos manuais e instrução moral e cívica. Para além dessa formação, os atos rotineiros tinham um papel essencial, rezas, festas e comemorações religiosas marcavam para sempre a "alma pura das jovens".

Deste modo, a escola não é apenas, como bem observa Forquin: 
[...] um local onde circulam fluxos humanos, onde se investem e se gerem riquezas materiais, onde se travam interações sociais e relações de poder; ela é também um local - o local por excelência nas sociedades modernas - de gestão e de transmissão de saberes e de símbolos [...] (1992, p. 28).

Regulando o ritmo das suas horas e dias pela prática religiosa, a mulher, louvada como esposa e mãe, é o suporte fundamental do catolicismo do século XIX. Desse modo, coloca-se, pois no feminino esse suporte. A feminilização das práticas, da piedade, do clero, aí está para demonstrá-lo. Essa mudança perceptível de atitude leva Michelet, a dizer que "Deus muda de sexo", uma clara alusão ao preponderante crescimento da participação feminina. (GIORGIO, 1994, p. 202).

Entre os diversos documentos analisados, o regimento de 1929, os relatórios municipais, as cartas pastorais, os impressos da época, o uso de entrevista, as imagens, os manuais indicados para uso do estabelecimento, entre outras fontes, nos possibilitaram um alargamento na compreensão do funcionamento de um internato dirigido pela Congregação de São José de Chamberry.

Fundada em 15 de outubro de 1648 em Puy, na França, pelo Padre Jesuíta Jean Pierre Medaille. A própria localização dessa congregação em Chamberry, não é por acaso. A forte presença de luteranos e calvinistas durante o século XVI, levou a uma ação contra-reformista de capuchinhos e jesuítas. "Um colégio de jesuítas é criado em 1565 em Chamberry, depois outro, em Thonon. Capuchinhos e jesuítas multiplicam as missões e empreendem a reconversão das populações do sul do lago de Genebra" (DEBESSE, 1974, p. 214-5).

O papel desempenhado por essa congregação no mundo e no Brasil particularmente, tinha como finalidade preservar os ideais católicos. Constituíam-se em partes integrantes da política de "romanização" do catolicismo em terras brasileiras. As Irmãs de São José introduziram essa mentalidade em seus colégios de São Paulo, Paraná, Rio Grande do Sul e em outras partes do território. Embora tenha essa congregação criado escolas externas e orfanatos, a forma de organização pedagógica por excelência foi o internato.

As formas arquitetônicas dos prédios, fechados para o exterior e parcialmente abertos para o interior, com muros e paredes que isolam, com espaços controlados, regulavam as práticas cotidianas das internas. Cerceando, proibindo, regrando, disciplinavam todos os atos, seja na forma de leituras recomendadas, seja tendo acesso as correspondências trocadas.

Enfim, isoladas do mundo, as internas mais facilmente absorviam os padrões e normas da instituição, adquiriam uma "boa" educação católica, uma base humanista alicerçada em determinados autores, um polimento social compatível com o papel que iriam desempenhar na sociedade.

\section{O Colégio São José}

Por iniciativa do Intendente Municipal, José Barbosa Gonçalves, conjuntamente com o Bispo de Porto Alegre, Dom Cláudio José Gonçalves Ponce de Leon, um grupo de Irmãs da Ordem de São José de Chamberry estabelece um educandário feminino na cidade de Pelotas no ano de 1910. Coube a Madre Ephrém Blanc, Visitadora que respondia interinamente pela Província, atender a demanda da Intendência Municipal, designando para cumprir essa missão a Madre Saint Maurice Reichmoz, bem como, as Irmãs Maria Alice Rellier, Jean Marquis Ract, Lídia Nicoline e Albina Derordi.

Não possuindo um prédio próprio para o funcionamento da instituição, o Intendente Municipal, José Barbosa Gonçalves, cede provisoriamente uma propriedade sua - um prédio localizado na Rua 15 de Novembro, esquina Rua Gomes Carneiro - no intuito de logo viabilizar o início do funcionamento da escola, e para tanto, também providencia material escolar, particularmente, mesas e cadeiras.

Oficialmente, a abertura do novo educandário 
ocorre em 19 de março de 1910, data extremamente significativa para a referida Ordem, tendo em vista tratar-se do dia de seu onomástico. Papel preponderante teve a Sociedade Literária e Caritativa das Irmãs de São José, pois em curto espaço de tempo o novo estabelecimento estava recebendo alunas em prédio próprio, localizado até hoje na Rua Félix da Cunha.

No ano de 1916, finalmente é construído um prédio com finalidade específica de casa educacional, segundo os preceitos da pedagogia da época.

Em local bem central o moderno e sólido prédio do acreditado Colégio São José é todo iluminado a luz elétrica, com amplas e confortáveis acomodações, obedecendo todas aos preceitos da mais rigorosa higiene. Em todas as aulas, dormitórios, salões e gabinetes de estudos, etc. Nota-se exemplar organização, rigoroso asseio e muito bom gosto. $\mathrm{O}$ curso completo do Colégio São José é de 08 anos sem contar o jardim da infância, e abrange todas as matérias do curso primário e secundário, ensinando-se a língua francesa e toda a espécie de trabalhos de agulha, ginástica de salão e civilidade. Tem também cursos facultativos de inglês, italiano, música e pintura. (CARRICONDE, 1922: s/p.).

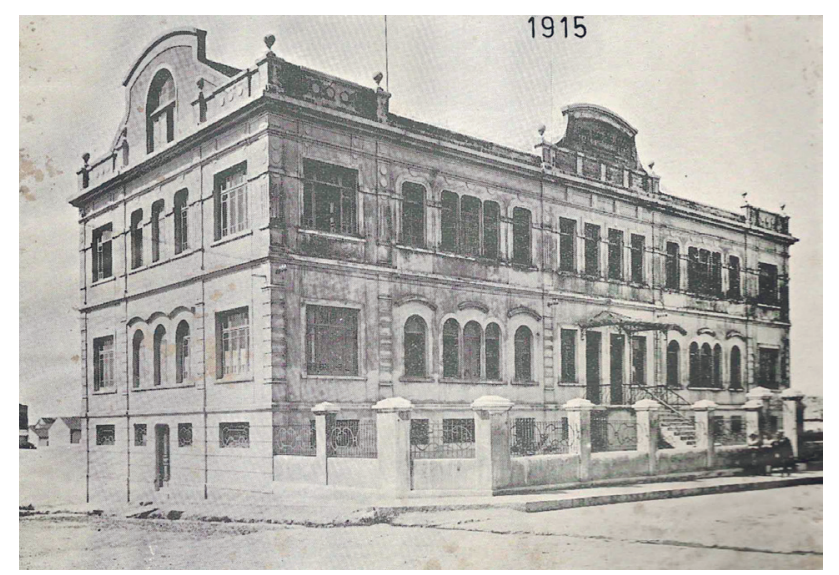

Prédio construído para o Colégio, fotografia de 1915. Fonte: Arquivo particular de Eduardo Arriada.
De forma impactante o novo prédio demarcava claramente uma ostentação de superioridade, perpetuando uma "áurea" de poder. O estabelecimento escolar e seu entorno físico, ou seja, áreas adjacentes, jardins e espaços verdes (praças, parques, hortas, pomares, etc.), fachadas, murros, calçadas, capelas, entre outros ornamentos, tornam-se elementos vitais como aparatos de sedução e convencimento das potencialidades de uma instituição, como expressa Escolano (1998), a arquitetura escolar para além de um espaço com determinadas funções, impõe-se como programa, como discurso que institui em sua materialidade um sistema de valores, de ordens, de disciplina e regramentos. Os prédios escolares, em certo sentido, foram pensados para serem espaços disciplinadores, espaços de controle e organização das práticas escolares.

O papel desempenhado pelo Colégio São José com certeza deixou marcas em diversas gerações. Nas diversas relações construídas dentro das instituições escolares, podemos dizer que a dimensão pedagógica constitui-se num principio que para além do instituído, evolui e transforma-se no e pelo processo educativo. Dentro dos murros escolares, o cotidiano, os hábitos, as rotinas, as práticas escolares, revelam sujeitos frágeis que "suportam a adaptação e a mudança, pelo que a educação e, por conseqüência, a escolarização são processos de colonização ideológica, cultural e afetiva" (MAGALHÃES, 2004, p. 63).

\section{Estado, Igreja e a educação da mulher}

Em relação à educação feminina, desde o final do século XIX, o discurso sobre a necessidade de uma melhor formação para o "sexo frágil" se faz presente. Articulada aos princípios da modernização da sociedade, que em parte jogava algumas mulheres no mercado de trabalho, uma forte preleção se fazia ouvir: a do pensamento positivista, que pregava que às mulheres cabia o relevante papel de dar continuidade as suas "vitais", "importantes" e "decisivas" atividades domésticas, só que agora, numa extensão do lar, ou seja, desenvolver essas aptidões no labor escolar. A elas ficava a 
responsabilidade e o papel de instruir os jovens da nascente nação brasileira, afinal, "[...] elas deveriam ser diligentes, honestas, ordeiras, asseadas [...]" (LOURO apud PRIORE, 2007, p. 447).

Esse lento processo, conhecido como "feminização do magistério", mesmo com algumas vozes contrárias, acabou marcando de maneira forte as primeiras décadas republicanas no Brasil. Justificadora de uma aptidão natural para lidar com as crianças, surgia uma possibilidade real de inserção no mercado de trabalho, tanto para as jovens oriundas de uma camada social mais baixa, como àquelas advindas das famílias mais abastadas. Dentro deste contexto, é engendrado um discurso que valoriza características tidas como da mulher: tolerância, docilidade, paciência, amorosidade, etc. Não apenas os positivistas reforçavam essas características, mas a própria Igreja Católica as ressaltava. Isso em parte redundou numa imagem das professoras como trabalhadoras servis, castas, dedicadas e gentis, tendo como contrapartida baixos salários, carreira desprestigiada e submissão ao domínio masculino ${ }^{1}$.

Inicialmente estabelecidas em São Paulo no ano de 1859, a Congregação das Irmãs de São José, oriundas de Chamberry na Sabóia, logo expandem o ideário doutrinário do ultramontanismo ${ }^{2}$ para outras partes do Brasil. Tanto em São Paulo, como em outras regiões, mesmo tendo criado escolas externas e orfanatos, o modelo pedagógico por excelência adotado foi o internato (MANOEL, 1996, p. 50).

Com o estabelecimento da República, desfeita a união estreita entre Estado e Igreja dominada pelo princípio do padroado ${ }^{3}$, pode a Igreja expandir-se. $\mathrm{O}$ regime de padroado impunha um rígido controle desta última, "tornando letra morta a legitimidade das normas canônicas e brecando quaisquer possibilidades de expansão organizacional" (MICELI, 2009, p. 22).

Embora tenham ocorrido diversas reformas educacionais propugnadas pelos republicanos, existindo inclusive uma ênfase no processo de laicização, eliminação do ensino religioso nos estabelecimentos públicos, óbices consideráveis ao ensino confessional, concorrência crescente das escolas protestantes, foi nesse período que o ensino secundário se constituiu como a alavanca mais dinâmica e rentável dos estabelecimentos religiosos.

A Igreja brasileira pós-separação teve de lidar com dois interlocutores sociais cujas demandas por vezes se revelavam contraditórias. De um lado, o Vaticano, empenhado na imposição às Igrejas da periferia de um modelo extremado de "romanização", e, de outro, os benfeitores abastados, os clãs oligárquicos, os governos e lideranças estaduais desejosos de cercear a influência eclesiástica sobre os negócios temporais e, ao mesmo tempo, abrindo espaços à presença da Igreja em domínios de atividade como o sistema de ensino (MICELI, 2009, p. 31).

Entre 1872 e 1920, um número expressivo de congregações européias se estabelece no Brasil. Voltadas particularmente para o trabalho educativo nos colégios, além do atendimento de doentes, crianças e velhos. Desse modo, diversos educandários (masculinos e femininos), asilos e orfanatos são criados. (NUNES, 2007; AZZI e GRIJP, 2008).

Articulando os desejos da Igreja e os interesses dos "clãs oligárquicos", instituições educativas são montadas. Nesse bojo diversos estabelecimentos femininos são erguidos por todo território nacional. Em fins do século XIX, as instituições religiosas católicas detinham praticamente o monopólio da educação no Brasil: das 4.600 escolas secundárias, $60 \%$ pertenciam à Igreja e gozavam de enorme prestígio. (NUNES, 2007).

Esse período histórico, ou seja, as décadas finais do século XIX, e as primeiras décadas do século XX, pode ser caracterizado pela consolidação da hegemonia ultramontana, sendo a principal estratégia utilizada pela Igreja Católica para a consolidação desse processo a implantação de uma rede de ensino confessional baseada na atuação das congregações religiosas e de uma intricada relação com as estruturas sociais 
conservadoras então hegemônicas na República Velha. (TAMBARA, 2006).

A vinda das Irmãs de São José para a cidade de Pelotas contou com o forte empenho do Intendente Municipal José Barbosa Gonçalves, demonstrando os estreitos vínculos entre o poder secular e o poder temporal. Coube ao mesmo não apenas matricular sua filha, como ainda ceder uma de suas propriedades em caráter provisório, bem como providenciar os materiais necessários para o seu funcionamento.

\section{Disciplinando condutas}

O internato impunha uma educação altamente disciplinada, cerceadora de qualquer iniciativa que questionasse os princípios organizativos da Congregação. Os altos muros e a vigilância constante não permitiam um espaço de liberdade às alunas, ao contrário, todo movimento era controlado, saídas e entradas não eram permitidas sem autorização.

Os regimentos ${ }^{4}$ eram minuciosos em detalhar esse controle, conforme rezavam determinados artigos: "Art. 44. As pensionistas estão constantemente sob a vigilância das professoras, tanto nos recreios e passeios, como nos trabalhos escolares". Além do mais estabeleciam com anterioridade certas normas: "Art. 51. Não se aceitam alunas que tenham sido eliminadas de outros colégios".

$\mathrm{O}$ requinte do disciplinamento atingia até a fiscalização das correspondências e das leituras, podendo certas obras serem parcialmente censuradas, ou até mesmo proibidas. $\mathrm{O}$ artigo 54 não deixa margem para dúvidas: "Cartas, pacotes e outros objetos que forem mandados as alunas, deverão passar pelas mãos da Diretora; não é permitido usar livros que não tenham sido apresentados e aprovados".

Isoladas do mundo, muito pouco era permitido às alunas. Mesmo as saídas eram rigorosamente controladas. O detalhamento dessas regras nos permite inferir a enorme preocupação com a saída das alunas internas, pois as mesmas, caso praticassem atos condenáveis poderiam denegrir a imagem do Colégio. Regra perfeitamente clara e incisiva estabelecida no artigo 30: "Procedimento repreensível fora do Colégio, que possa prejudicar a boa reputação do mesmo, está sujeito a castigos escolares".

Eis o que consta no artigo 55: "As pensionistas que tiverem na cidade parentes ou correspondentes, poderão, a pedido dos pais, passar os domingos de saída, isto é, o $2^{\circ}$ e $4^{\circ}$ de cada mês. O Colégio não se responsabiliza por nada que aconteça, estando as alunas fora de sua tutela”. O artigo 56, complementava as preocupações relativas a conduta das alunas: "Em nenhum caso será permitido a uma aluna pernoitar fora do Colégio, a não ser em companhia dos pais e com prévio aviso dos mesmos. A falta neste ponto é motivo de exclusão". (REGIMENTO, 1929).

$\mathrm{O}$ uso do uniforme dentro do recinto do Colégio, como fora dele, assegurava o controle a visibilidade e o pertencimento das internas a essa instituição, conforme reza o artigo 32: "É obrigatório para todas, o uniforme do Colégio".

O Regimento de 1929 do Colégio São José deixava explícita a seguinte finalidade: “[...] proporcionar às suas alunas uma sólida educação física, intelectual, moral e religiosa [...]" (Art. 1). Esses aspectos eram endossados e salientados nos discursos:

Com o novo Colégio que surgia, surgiam também ensinamentos novos e uma disciplina diferente, fatores, aliás, que muito haveriam de contribuir para o progresso e a cultura de nossa cidade. Qual de nós poderá esquecer jamais a figura ímpar de Mére Saint Maurice, percorrendo as aulas e cuidando a saída das alunas? Seus conselhos, suas lições nunca serão esquecidos por nenhuma de nós. O Colégio São José soube sempre incutir em suas alunas o desejo constante de aperfeiçoamento; a ânsia de saber cada vez mais; o amor a tudo que é belo, puro e elevado (FERREIRA, Oração, 1960, p. 08).

Destarte, ausentes do mundo, as alunas facilmente absorviam os ensinamentos e preceitos educativos da Congregação, baseados no projeto de formação de um alicerce religioso, sobre o qual se ergueria uma sociedade de acordo com os critérios e propostas da 
Igreja, isto é, "[...] uma sociedade católica, ordeira, hierarquizada, moralizada, antimoderna, antiliberal, antifeminista [...]”. (MANOEL, 1996, p. 52).

No geral, o Colégio São José atendia três modalidades diferentes de matrícula: internato, externato e orfanato, sendo que, posteriormente, também foi criada a modalidade de matrícula para o semi-internato. Em relação aos cursos, estavam divididos em: a) um curso de principiantes; b) cinco cursos preliminares; c) um curso de admissão aos ginásios; d) um curso de admissão às escolas complementares; e) um curso complementar; f) um curso ginasial. (Art. 4). O artigo 5 salientava que os programas são distribuídos de modo a permitir o acesso de um para outro curso, sem prejuízo da matrícula direta (REGIMENTO, 1929).

A organização dos tempos no Colégio São José dividiase em dois turnos: uma na parte da manhã, outro na parte da tarde. Durante todo o ano letivo, a entrada das alunas era realizada às $08 \mathrm{~h} 30 \mathrm{~min}$ da manhã, findando esse primeiro turno às $11 \mathrm{~h} 30 \mathrm{~min}$ e o segundo turno iniciava às $13 \mathrm{~h} 30 \mathrm{~min}$ e finalizava às $16 \mathrm{~h}$. Quartas e sábados as aulas só se desenrolavam no primeiro turno, ficando o segundo turno suprimido (RELATÓRIO, 1944).

Grande parte dessa estrutura estava voltada para o internato, proposta que se evidenciava tanto nos regulamentos, como nos discursos, afinal constituíase como o espaço onde as estratégias de dominação e execução do projeto educacional mais se efetivavam.

O Colégio é dirigido competentemente pelas carinhosas e dedicadas Irmãs francesas da Congregação de São José, que não poupam esforços em dar, ao elevado número de meninas que freqüentam suas aulas, uma séria instrução religiosa, literária e científica, uma perfeita e sólida educação elevando seu espírito e seu coração, preparando-as assim para todos os deveres que as esperam no mundo, como filhas, esposas ou mães (CARRICONDE, 1922, s/p.).

Formar as jovens na prática das virtudes que convêm a uma boa moça de família; incutir hábitos de disciplina, modéstia, e respeito à religião; revestir os seus espíritos com uma instrução apropriada as suas idades e prepará-las adequadamente para as futuras obrigações. A finalidade da educação ministrada nesses internatos católicos atingia dois aspectos distintos, mas complementares: a educação e a instrução. Quanto à instrução, cabia propiciar o contato com determinadas áreas do saber, principalmente o estudo das línguas, das ciências, da história e da matemática. Em relação à educação, cabia formar o caráter e as condutas das educandas dentro dos preceitos e valores do cristianismo. Além do mais, as atitudes e comportamentos eram seriamente cobrados, como podemos verificar no texto denominado "Boas Maneiras":

Atitude na rua. Não se fala alto; evitam-se gargalhadas escandalosas, não se corre, não se fazem movimentos bruscos. Quando duas pessoas estão juntas, caminhando a pé, de automóvel, etc., a pessoa mais moça ou de posição menos elevada, dá sempre a direita à mais velha ou à superior. $\mathrm{O}$ cumprimento deve ser amável, geralmente acompanhado de um sorriso e de leve inclinação da cabeça, demonstrando a nossa consideração e o nosso prazer. Um aluno nunca deixa de cumprimentar seu mestre $(\mathrm{O}$ SÃO JOSÉ, 1960, p. 62).

Assim sendo, o objetivo mais amplo era formar jovens polidas, meigas, educadas e cultas, mas acima de tudo, cristãs e crentes que professassem os princípios do catolicismo ultramontano. Para isso, uma prática diária de sala de aula e a vivência cotidiana nos outros espaços, balizada por um rígido e severo código de condutas, concretizavam esse ideal.

$\mathrm{O}$ internato cumpria esse desiderato por meio de uma vigilância constante, todos os gestos, todas as atitudes, todos os movimentos eram minuciosamente controlados, de maneira que atitudes, comportamentos, gestos de caráter individual fossem coibidos, cerceados, e todas indistintamente tivessem comportamentos iguais, padronizados, sem marcas 
pessoais, sem individualidades (FOUCAULT, 1984; CARON, 1996).

Um conjunto de regras determinava que padrões e comportamentos a mulher deveria adotar: postura, conduta, gestos, fala, vestimenta e formas de cumprimento, tudo era controlado e rigorosamente incutido. As normas eram para serem obedecidas, jamais questionadas ou rompidas. O depoimento de uma exinterna ${ }^{5}$ reafirma essa postura, já que cotidianamente era explicitado o seguinte princípio: "Pura, dura e segura”, assim devia ser a conduta das pensionistas.

$\mathrm{O}$ poder disciplinador atua com o intuito de controlar, incitar, organizar, estimular, inibir, ou seja, buscam enquadrar as internas num modelo considerado ideal, "alunos dóceis e úteis". Somente em casos extremos, onde esse controle e possíveis sanções não tiveram eficácia, serão permitidos mecanismos mais violentos, caso da expulsão determinada pelo artigo 56: "Em caso nenhum será permitido a uma aluna pernoitar fora do Colégio" (a não ser em companhia dos pais).

Para Foucault (1984, p. 153), o sucesso do poder disciplinador ocorre de maneira bastante clara, se deve ao uso de instrumentos simples: o olhar hierárquico, a sanção normalizadora e sua combinação num procedimento que lhe é específico, o exame.

O olhar hierárquico reflete-se no modelo de construções adotadas para os colégios, toda uma problemática se desenvolve, não mais uma arquitetura para ser admirada, mas agora "para permitir um controle interior, articulado e detalhado - para_tornar visíveis os que nela se encontram". Não mais o simples encarceramento e fechamento, não mais o murro espesso, a porta sólida, que impedem de sair ou de entrar, tudo começa a ser substituído pelo "cálculo das aberturas, dos cheios e dos vazios, das passagens e das transparências" (FOUCAULT, 1984, p. 154-155).

O uso do uniforme implicava padronizar uma homogeneidade entre todas, inibir vaidades e ocultar as formas sensuais do corpo feminino. $\mathrm{O}$ Art. 59 determinava o seguinte para as internas:

Cada aluna deve trazer o enxoval composto dos seguintes objetos: $§ 1^{0}$. Três uniformes: dois diários e um para os domingos, de sarja azul marino; $\S$ $2^{\circ}$. Um casacão para o inverno; $\S 3^{\circ}$. Três pares de calçados fortes e pretos (REGIMENTO, 1929).

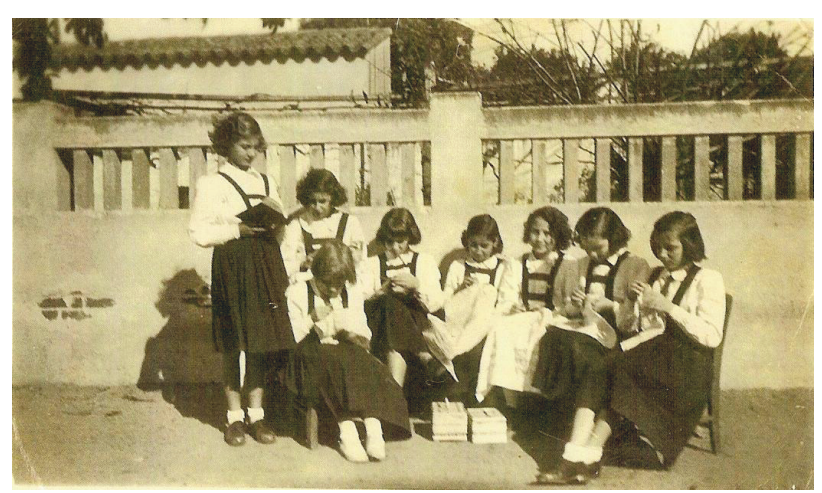

Grupo de alunas pensionistas, fotografia de 1952.

Da direita para a esquerda ao fundo: Sonia Pereira (em pé), Iara Lopes, Lurdes Oliveira, Genoveva Feijó Arriada, Maria Elva Arriada, Maria Mila Feijó Arriada e Zulma Marcatto. Na primeira fila: Cleunice (tênis branco). Fonte: Arquivo particular de Eduardo Arriada.

Nesta foto das pensionistas, observamos um grupo no pátio interno do Colégio (próximas ao antigo galinheiro), desempenhando diversas atividades socialmente valorizadas no universo feminino, uma vez que umas costuram, outras bordam, enquanto a primeira da esquerda, em pé, lê. Todas portam o típico uniforme, saias longas, cores neutras (branco e azul marinho), meias brancas e sapatos pretos.

As internas, além do uniforme, deveriam trazer um enxoval completo, ou seja, aqueles elementos necessários para permanecer no estabelecimento, entre outras obrigações salientamos as mencionadas no Art. $59 \S 4^{\circ}$ :

[...] um colchão de $1,80 \mathrm{~cm}$ de comprimento e $70 \mathrm{~cm}$ de largura, 2 travesseiros com 6 fronhas, 1 acolchoado, 1 cobertor, 2 colchas brancas, 6 lençóis, 12 camisas, 4 camisetas de dormir, 6 toalhas de rosto e 2 de banho, 2 camisas 
de banho, 4 guardanapos, 2 sacos para roupa servida, uma escova de dentes, pente, 4 saias brancas, 24 lençóis, 1 mosquiteiro; 12 pares de calças, 12 pares de meia, 1 caixa de costura com tesoura, dedal, agulhas, linhas, botões, colher de sopa, de chá, garfo, faca, copo de metal, etc (REGIMENTO, 1929).

De acordo com o depoimento de Genoveva Feijó Arriada, todas as peças do enxoval deveriam ser marcadas com o nome e número fornecido às alunas quando de sua admissão, inclusive, a mesma ainda lembrava que seu número era o 48.

Constituído de três andares: porão, primeiro pavimento e segundo pavimento, a ala das internas estava localizada no segundo pavimento, com frente para a parte interna do prédio, isto é, com as janelas voltadas para o jardim interno. Suas dimensões compreendiam 34 metros de comprimento, com 6,40 de largura. Pelas plantas baixas constantes no arquivo morto da escola, podemos verificar que esse vasto dormitório constava de 40 leitos, existindo na mesma peça diversas pias (lavatórios) e ao lado, próximo à porta de entrada ficavam os banheiros.

Os leitos possuem mesas de cabeceiras individuais, adequadas para seus fins e para maior comodidade de cada uma das alunas, em outra sala anexa, ficam colocados armários especiais, numerados, cujas chaves ficam entregues as alunas respectivas. Para suprir necessidades decorrentes de uma casa de ensino que possui alunas internas, o Ginásio São José possui uma enfermaria que dispõe de todo material curativo de urgência, com mesas e aparelhos apropriados. Também funciona um gabinete médico, cuja maior finalidade é justamente a atividade biométrica, orientado pelo Dr. Osvaldo Medrado, médico profissional do estabelecimento (RELATÓRIO, 1944, p. 03-04).

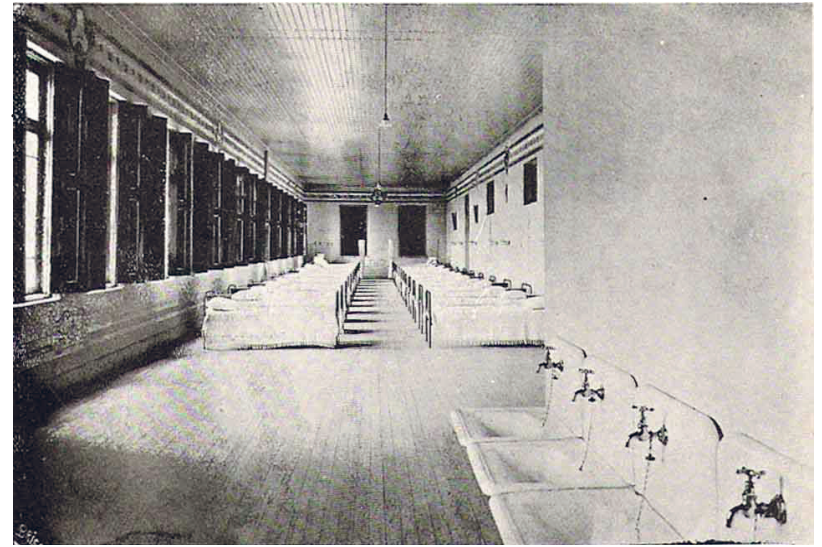

O dormitório do Collegio São José

Fonte: Álbum de Pelotas, 1922

Geralmente, as jovens eram agrupadas por faixas etárias no dormitório, as menores, as maiorzinhas e as maiores. Antes de dormir sempre rezavam, momento invariavelmente sucedido pelo silêncio absoluto. $\mathrm{Na}$ década de 50 , ao redor das camas existia uma cortina, possibilitando certa privacidade, porém, acompanhada de um controle constante, pois, sabedoras que nem sempre as regras eram cumpridas, as Irmãs inculcavam na mente das jovens, que todos os atos ilícitos, os atos impuros, os atos de rebeldia, eram constantemente vigiados pelos olhos de Deus, o pai-todo-poderoso que tudo via, de tudo sabia. Diversos depoimentos de internas atestam essa realidade: acima dos olhos e ouvidos humanos, estava o olhar permanente de Deus.

Para além das normas de boa conduta, existia um currículo estruturado para o universo feminino. Em 1917, o Curso Completo tinha a duração de sete anos e o programa de estudos era o seguinte: doutrina cristã; leitura e caligrafia; línguas portuguesa e francesa (gramática, literatura, arte de redigir e compor, análise, declamação, etc.); aritmética, geometria, álgebra, geografia e cosmografia; história sagrada, pátria e universal; lições de coisas; história natural; noções de física e química; desenho linear e perspectiva; solfejo e canto. Estudava-se ainda toda espécie de trabalhos de agulha, ginástica e civilidade. Como Curso Facultativo ensinava-se: alemão; inglês; italiano; piano; violino; bandolim; pintura a óleo e aquarela; pirogravura, etc. (PRIMEIRO LUSTRO DA DIOCESE DE PELOTAS, 1917, p. 295-296). 
O programa de 1929, na essência muito pouco alterou o programa de 1917, e estabelecia as seguintes disciplinas para o Curso Elementar: $1^{\circ}$ linguagem oral e escrita; $2^{\circ}$ aritmética e geometria; $3^{\circ}$ instrução moral e cívica; $4^{\circ}$ geografia; $5^{\circ}$ ciências físicas e naturais; $6^{\circ}$ desenho; $7^{\circ}$ educação física; $8^{\circ}$ música, canto, teoria e solfejo; $9^{\circ}$ trabalhos manuais. Para o Curso Complementar, de três anos, estavam previstas as seguintes disciplinas: $1^{\circ}$ português; $2^{\circ}$ francês; $3^{\circ}$ aritmética álgebra e geometria com desenho linear; $4^{\circ}$ geografia geral, corografia do Brasil, cosmografia; $5^{\circ}$ desenho figurado; $6^{\circ}$ história geral, do Brasil e ensino cívico; $7^{\circ}$ ciências (física, química, história natural e higiene); $8^{\circ}$ economia doméstica; $9^{\circ}$ música e canto coral; $10^{\circ}$ trabalhos manuais; $11^{\circ}$ educação física; $12^{\circ}$ pedagogia e prática profissional (REGIMENTO, 1929).

Os livros mais usados em sala de aula seguiam as orientações gerais da Congregação de São José. Para o ensino do francês foi usada a "Gramática" de Halbout ${ }^{6}$, além de diversas obras editadas na "Coleção de Livros Didáticos F.T.D"7, como: "Le Guide de l'enfance"s, "Le Deuxième livre d'André" e "Antologia Francesa"10. Deste último livro, destacamos do prólogo o seguinte trecho:

Restringiu-se a escolha aos melhores, aos verdadeiros Mestres. Os trechos apresentados são eminentemente educativos. Na escola destes grandes modelos, a mocidade sente suas faculdades se engrandecerem, seus conceitos tomarem precisão, vivacidade, energia e segurança, seu juízo encaminhar-se para o bem e a verdade, seu espírito nutrir-se de grandes pensamentos e chegar as culminâncias da beleza moral e literária.

Outro autor adotado foi o Cônego José Inácio Roquete, sua "Seleta" ${ }^{11}$ era considerada não apenas um bom manual de estudo, mas também modelo de civilidade e bons costumes, contendo uma seleção de trechos de diversos autores franceses. O Cônego salientava no prólogo de sua obra:
Os meninos achariam neste livro um alimento mais são, e não menos agradável, que o que ordinariamente lhes fornecem na freqüente leitura do Telêmaco e das Fábulas de la Fontaine. Os belos trechos de história, os exemplos sublimes de virtude, as anedotas interessantes, as agudezas engraçadas, as réplicas chistosas e a tempo, agradam geralmente aos meninos, e lhes são de mais proveito que todas essas ficções românticas, mais ou menos sensuais, em que reina ordinariamente uma moral relaxada, e por vezes egoísta e pouco cristã.

Os trechos selecionados pelo Cônego José Inácio Roquete tinham como intuito formar crianças leitoras, mas sem macular a sua inocência e pureza, por isso eram suprimidas passagens que por ventura abordassem questões vinculadas ao sexo. Embora não negasse a importância de uma obra como "Telêmaco", condenava a mesma pelas seguintes razões:

O próprio Telêmaco, não obstante ser obra de um virtuoso prelado, tem bastantes páginas cuja leitura é, por desgraça, bem perigosa para a gente moça. Todas aquelas descrições do templo de Vênus, da ilha encantada dos amores e do império de Cupido; todas aquelas pinturas vivas e naturais da formosura das ninfas, de seus cantares, brincos e divertimentos, de suas caçadas e enredos amorosos, exaltam a imaginação, enfraquecem o pejo, desordenam os afetos honestos, apressam e precipitam as inclinações viciosas, e inspiram tédio as coisas sérias e devotas. (ROQUETE, Prólogo, 1916).

Os manuais de história mais usados nos primeiros anos de funcionamento do Colégio foram: para a História Universal o livro de Mons. Daniel ${ }^{12}$, Bispo de Coutances e de Avranches, "Curso de História 
Universal" tradução e adaptação de Joaquim Maria de Lacerda; assim como o "Compêndio de História Universal" de Joaquim Maria de Lacerda ${ }^{13}$. Outro manual bastante utilizado era o do Padre Raphael Galanti. ${ }^{14}$, sendo que o mesmo autor, também era a principal referência quanto à História do Brasil ${ }^{15}$.

Para o ensino do inglês ordinariamente utilizavam os manuais editados pela Livraria Paulo de Azevedo, "Coleção F.T.D.", sendo que, iniciavam pelo texto "Língua Inglesa: primeiro método"16, e logo após passavam para a "Primeira Seleta Inglesa" "17; frisando que: “[...] o aluno que já estudou esse primeiro método de língua inglesa, terá grande facilidade e singular proveito em traduzir esta Primeira Seleta Inglesa" (1926, p. 03). As marcas da religiosidade estavam sempre presentes, o primeiro texto trabalhado na Seleta é elucidativo: "The presence of God".

Para a língua portuguesa, os mesmos princípios eram adotados, via de regra, davam preferência para as obras editadas pela "Coleção F.T.D.”. Os diversos livros tratavam do curso preparatório, elementar, médio e superior, onde então, passavam para as Antologias, terceiro e quarto livro ${ }^{18}$.

Em relação ao latim, estudavam preferencialmente as obras da "Coleção F.T.D.", particularmente a Primeira Seleta Latina ${ }^{19}$, que continha trechos de Lhomond, Eutrópio, Fedro, entre outros; ao final um léxico para auxiliar os alunos. Algumas edições mais antigas ainda eram usadas, como por exemplo, as diversas edições ${ }^{20}$ da Livraria Guillard, Aillaud \& Cia., com notas e comentários de José Inácio Roquete. A partir da década de 40, dois autores passam a ser bastante usados, José Lodeiro ${ }^{21}$ e Milton Valente ${ }^{22}$.

Embora a centralidade da educação católica não fosse a profissionalização feminina, mais tarde, com o estabelecimento da Escola Normal (1942) duas obras de caráter pedagógico passam a ser bastante usadas. Uma delas foi o livro escrito por Teobaldo Miranda Santos ${ }^{23}$, a outra pelas Madres Francisca Peeters e Maria Augusta de Cooman ${ }^{24}$. O livro das irmãs Peeters e Cooman, fornecia um panorama geral da Pedagogia e na parte final dedicava um capítulo sobre a história da educação brasileira, contendo ainda um apêndice "Esboço histórico da educação da mulher nos tempos modernos". A obra procurou contemporarizar o universo feminino com as mudanças que surgiam no alvorecer do século XX.

Até o surto do movimento feminista que começou em fins do século XIX, [...] a educação das classes abastadas tinha um cunho de formação literária e de distinção notável. Não se preocupavam as moças da procura duma carreira. As ciências físicas e naturais eram ensinadas como complemento da instrução e meio de conhecer de compreender algo do movimento científico crescente; mas a literatura, a história, as disciplinas formadoras da cultura geral dominavam as demais (PEETERS; COOMAN, 1937, p. 149).

Por não estarem imbuídas de um espírito profissionalizante, de pouco valiam certos conhecimentos: "[...] a técnica que predomina o caráter educativo nessas mesmas ciências, de nada aproveita ao espírito feminino, mais apto para as ciências de cunho literário e até filosófico do que para os estudos de orientação profissional" (PEETERS; COOMAN, 1937, p. 149).

Neste tempo de especialização deformadora a defesa e a conservação da cultura geral deveria pertencer à mulher instruída, bem como a manutenção do bom tom e da distinção que desaparecem dum modo lamentável da nossa sociedade hodierna. A mulher por essência educadora, deveria ser acima de tudo educada. Certos estudos tendem a diminuir nela a fineza e a delicadeza dos sentimentos. De mais a mais a acumulação das matérias de ensino nem sempre deixa tempo para cultivarem-se os dotes propriamente femininos (PEETERS; COOMAN, 1937, p. 149).

Percebendo a irredutibilidade das mudanças, as Irmãs de São José procuraram aos poucos adequarem-se aos novos tempos, para além da 
profissionalização das jovens, buscaram manter a base construída, ou seja, ornar o espírito dentro de uma sociedade patriarcal.

\section{Considerações finais}

A proposta educacional do Colégio de São José alicerçada nas normas e padrões da Congregação de Chamberry buscava modelar e disciplinar as condutas das internas segundo os princípios e valores da Igreja Católica, agora sob a égide da romanização. Esse modelo de educação estava voltado para a formação de moças educadas, amáveis, meigas e respeitadoras de toda uma estrutura que as relegava ao papel subsidiário de auxiliares dos homens. As normas, os programas, os preceitos, visavam formar mulheres para a vida familiar e não necessariamente para um mercado de trabalho que começava a estruturar-se, a exceção seria o magistério.

Nos diversos textos que analisamos essa questão reverbera constantemente: "a única educação possível" de ser adequada a uma mulher era o respeito, a consideração, a castidade, cabendo no máximo o papel de professora, o que não deixava de ser uma continuação das atividades domésticas, agora é mãe de diversos filhos.

As diversas "disciplinas-saber" estabelecidas no currículo eram típicas das camadas sociais privilegiadas. Tratava-se de saberes alicerçados na área das humanidades, onde o conhecimento de línguas estrangeiras, em particular o francês, era preponderante. A leitura de diversos textos baseava-se na memorização e na exploração dos conteúdos moralizantes, principalmente daqueles que salientavam os valores religiosos.

Desse modo, estabelece-se uma "cultura escolar" que divide e disciplina o tempo na escola, tendo um papel crucial a adoção de novos métodos didáticos, novos programas, e novos manuais escolares. Como esclarece Julia (2001, p. 10-11): "poder-se-ia descrever a cultura escolar como um conjunto de normas que definem conhecimentos a ensinar e condutas a inculcar, e um conjunto de práticas que permitem a transmissão desses conhecimentos".

Esse modelo de escola submete professores e alunos a uma educação altamente especializada no controle e disciplinamento de "corpos e espíritos"; estabelece regras e ritos; passa a valer-se de elementos de controle, como é o caso da chamada; padrões e comportamentos que permanecerão presentes durante muito tempo nas escolas.

A preocupação básica das Irmãs de São José era formar as jovens dentro de princípios que reforçassem a ordem, as boas maneiras, o respeito e a obediência, desde o ato de levantar até o deitar, traduzido num rol de obrigações, práticas de sociabilidades, rotinas e aprendizagens, visando um fim precípuo: formar moças educadas, cultas, obedientes, crentes em Deus e seguidoras das normas sociais da sociedade vigente.

\section{Notas}

1 Sob esse aspecto consulte-se: Bourdieu (2005).

2 Esse momento histórico, também conhecido como o processo de romanização, passa a afirmar que os brasileiros eram antes de tudo "católicos romanos" e não "católicos do Estado". Esse endurecimento da postura torna a Igreja mais intransigente em matéria de acordos com o Estado. Com o dogma da "infalibilidade do papa", passa a advogar que a verdade era sempre católica, e o erro, sempre liberal e protestante. Entre a alta hierarquia religiosa, predominava a ideia que tanto liberais, maçons, positivistas, como socialistas, lutavam para extinguir a Santa Sé. Assim, a Igreja devia estruturarse, unir-se e combater as "novidades nocivas do século".

3 Padroado Régio: "compromisso entre a Igreja Católica e o governo de Portugal que assegurava o exercício pleno do domínio político e religioso dos reis sobre a colônia, pois esses soberanos detinham o título de grão-mestre da Ordem de Cristo. Na prática, significava que o direito do padroado foi cedido pelo papa ao rei, que deveria promover a organização da Igreja em terras descobertas. Através do padroado, foi financiada a expansão do catolicismo no Brasil. Ao rei de Portugal cabia pagar as côngruas régias, arrecadar os dízimos, controlar a vinda de religiosos para a Colônia, escolher os bispos, criar paróquias, etc.”. (BOTELHO; REIS, 2003, p. 132).

4 Regimento do Colégio São José, editado em 1929, trata-se de um documento composto de 60 artigos, contendo ainda o Programa do Curso Complementar e do Curso Elementar.

5 Depoimento de Genoveva Feijó Arriada, realizado em 14 de fevereiro de 2008.

${ }^{6}$ HALBOUT, José Francisco. Gramática teórica $e$ 
prática da Língua Francesa. 20 ed. Paris: Livraria de Garnier Irmãos, 1907.

7 As obras editadas na Coleção F.T.D., estavam impregnadas de caráter religioso, e por isso mesmo eram aprovadas pela Igreja, como observamos em diversos trechos. A própria abreviatura em latim é reveladora: Deus, Pátria e Família (em tradução para o português).

8 DUMONT, Isidoro. Le Guide de L'enfance. Premier livre de lecture en français: vocabulaires, lectures, questionnaires pour la conversation, morceaux choises. Rio de Janeiro: Livraria Francisco Alves, 1922.

9 Le Deuxième Livre d'André. Choix de lectures courantes, instructives, morales, éducatrices et récitatión. Rio de Janeiro: Livraria Paulo de Azevedo \& Cia, 1935.

${ }^{10}$ Anthologia Franceza com numerosas annotações. Prosa e Verso dos autores dos séculos XVII, XVIII, XIX e XX. Rio de Janeiro: Livraria Paulo de Azevedo \& Cia., 1923.

${ }^{11}$ ROQUETE, J.I. Selecta Franceza ou Trechos extrahidos dos melhores autores francezes em Prosa e Verso. Revista e aumentada por Léopold Marcou. Paris; Rio de Janeiro: Aillaud, Alves \& Cia; Francisco Alves \& Cia., s/d [1916?].

${ }^{12}$ Curso de História Universal por Mons. Daniel traduzido e continuado até nossos dias pelo Dr. Joaquim Maria de Lacerda (Membro da Arcádia Romana). Rio de Janeiro: B.L.Garnier, 1889.

${ }^{13}$ LACERDA, Joaquim Maria de. Compêndio de História Universal. Rio de Janeiro: Nova Edição; H. Garnier, 1904. Composto para uso das escolas do Brasil, contemplava também História Sagrada, História do Brasil e Mitologia.

${ }^{14}$ GALANTI, Raphael. Compêndio de História Universal. 4 ed. São Paulo: Duprat \& Comp., 1907.

${ }^{15}$ GALANTI, Raphael. Lições de História do Brasil. 5 ed. São Paulo: Duprat \& Comp., 1913.

${ }^{16}$ Lingua Inglesa: primeiro método. Rio de Janeiro: Livraria Paulo de Azevedo \& Cia., 1931.

${ }^{17}$ Primeira Seleta Inglesa: my reading book - the first. Rio de Janeiro: Livraria Francisco Alves; Paulo de Azevedo \&Cia., 1926.

${ }^{18}$ Lingua Portuguesa: leituras variadíssimas. Antologia. 3 livro da Coleção F.T.D. Rio de Janeiro: Livraria Paulo de Azevedo \&Cia, 1922.

${ }^{19}$ GALIDIE, Luiz. Primeira Seleta Latina. Rio de Janeiro: Livraria Francisco Alves, 1926.

${ }^{20}$ Edições denominadas "Clássicos Latinos", abrangia textos de Cornélios Nepos, Cícero, Júlio Cesar, Horácio, Tito Lívio, Virgilio, entre outros.

${ }^{21}$ LODEIRO, José. Traduções dos textos latinos para uso dos ginásios, colégios e seminários. 1 ed. Porto Alegre: Ed. Globo, 1942.

${ }^{22}$ Em particular as várias séries do "Ludus"; primus, secundus, tertius, quartus e quintus. A maioria editada pela Livraria Selbach de Porto Alegre.

${ }^{23}$ SANTOS, Teobaldo Miranda. Noções de História da Educação. São Paulo: Comp. Editora Nacional, 1945.

${ }^{24}$ PEETERS, Francisca; COOMAN, Maria Augusta de. Educação: História da Pedagogia. São Paulo: Companhia Melhoramentos, 1937.

\section{Referências Bibliográficas}

ALMANACH DE PELOTAS 1913. Pelotas: Oficina Tip. do Diário Popular, 1913.

AZZI, Riolando; GRIJP, Klaus van der. (Org.). História da Igreja no Brasil: ensaio de interpretação a partir do povo. Terceira Época (1930-1964). Petrópolis: Editora Vozes, 2008.

BEOZZO, José Oscar. A Igreja entre a Revolução de 1930, o Estado Novo e a Redemocratização. In: FAUSTO, Boris (Direção). Tomo III. O Brasil Republicano. $4^{\circ}$ volume. Economia e Cultura (1930-1964). História Geral da Civilização Brasileira. São Paulo: Difel, 1984.

BOTELHO, Ângela Vianna; REIS, Liana Maria. Dicionário Histórico Brasil: Colônia e Império. $4^{\circ}$ edição. Belo Horizonte, Autêntica, 2003.

BOURDIEU, Pierre. A Dominação Masculina. 4 ed. Rio de Janeiro: Bertrand Brasil, 2005.

CARON, Jean-Claude. Osjovens na escola: alunos de colégios e liceus na França e na Europa (fim do séc. XVIII- fim do séc. XIX). In:LEVI, Giovanni; SCHMITT, Jean-Claude. História dos Jovens: a época contemporânea. Vol. 02. São Paulo: Companhia das Letras, 1996, p. 137-194.

CARRICONDE, Clodomiro. Álbum de Pelotas. Centenário da Independência. Pelotas: Livraria Universal Echenique \& Cia., 1922.

CHERVEL, André. La Culture Scolaire: une approche historique. Paris: Belin, 1998.

DALLABRIDA, Norberto. A Fabricação Escolar 
das Elites: o Ginásio Catarinense na Primeira República. Florianópolis: Cidade Futura, 2001.

DEBESSE, Maurice. A renascença. In: DEBESSE, Maurice; MIALARET, Gastón. (Orgs.). Tratado das ciências pedagógicas. História da Pedagogia. São Paulo: Companhia Editora Nacional, 1977.

ECHOS do Colégio Diocesano de São José. [Rio de Janeiro, Largo do Rio Comprido]. Rio de Janeiro: Léon de Rennes \& C., 1905.

ESCOLANO, Agustín. Arquitetura como programa: espaço-escola e currículo. In: ESCOLANO, Agustín e VIÑAO FRAGO, Antônio. Currículo, espaço e subjetividade: a arquitetura como programa. Rio de Janeiro: DP\&A, 1998.

FORQUIN, Jean-Claude. Saberes escolares, imperativos didáticos e dinâmicas sociais. In: Teoria e Educação. Porto Alegre, n 5, 1992, p. 28-49.

FOUCAULT, Michel. Vigiar e Punir. 3 ed. Petrópolis: Vozes, 1984.

Microfísica do poder. $12^{\circ}$ edição. Rio de Janeiro: Edições Graal, 1996.

GIORGIO, Michela de. O modelo católico [199-237]. In: FRAISSE, Geneviève; PERROT, Michelle. História das Mulheres no Ocidente. O século XIX. Porto: Edições Afrontamento, 1994.

JULIA, Dominique. A Cultura Escolar como objeto histórico. In: Revista Brasileira de História da Educação. Campinas: SBHE; Autores Associados. $\mathrm{N}^{\circ}$ 1, jan/jun 2001.

LOURO, Guacira. Mulheres na sala de aula. In: PRIORE, Mary Del. História das Mulheres no Brasil. 9 ed. São Paulo: Contexto, 2007.

MAGAlHÃES, Justino Pereira de. Tecendo nexos: história das instituições educativas. Bragança Paulista: Editora Universitária São Francisco, 2004.

MANOEL, Ivan. Igreja e Educação Feminina (1859-1919): uma face do conservadorismo. São Paulo: Ed. UNESP, 1996.

Os Colégios das "Freiras Francesas": um exemplo das relações entre Igreja Católica e Estado no Brasil (1859-1919). In: CARVALHO, Carlos Henrique de; NETO, Wenceslau Gonçalves. (Orgs.). Estado, Igreja e Educação: o mundo ibero-americano nos séculos XIX e XX. Campinas: Editora Alínea, 2010.

MELLO, Joaquim Ferreira de. Primeiro Congresso Católico Diocesano de Pelotas. Porto Alegre: Tipografia Pão dos Pobres, 1935.

MICELI, Sergio. A Elite Eclesiástica Brasileira (1890-1930). São Paulo: Companhia das Letras, 2009.

NUNES, Maria José Rosado. Freiras no Brasil. In: PRIORE, Mary Del. (Org.). História das Mulheres no Brasil. $9^{\circ}$ edição. São Paulo: Contexto, 2007.

O SÃO JOSÉ. O Colégio São José no seu cinquentenário (1910-1960). Ano X. No 1. Pelotas: Oficinas Gráficas do Instituto de Menores, 1960.

PEETERS, Francisca; COOMAN, Maria Augusta. Educação: história da Pedagogia. São Paulo: Cia. Melhoramentos, 1937.

PIO XI. Divini Illius Magistri (Sobre a educação cristã da juventude, 1927). Petrópolis: Vozes, 1974.

PIZANI, Maria Angélica Pinto Nunes. O cuidar na atuação das Irmãs de São José de Moutiers na Santa Casa de Misericórdia de Curitiba (1896-1937). Tese de Doutoramento em História. Curitiba, UFPR, 2005.

PRIMEIRO LUSTRO DA DIOCESE DE PELOTAS (1911-1916). Pelotas: Livraria Comercial, 1917.

REGIMENTO do Colégio São José de Pelotas. Pelotas: Livraria do Globo, 1929.

RELATÓRIO apresentado ao Conselho municipal em 20 de setembro de 1910, pelo Intendente José Barboza Gonçalves. Pelotas: Of. do Diário Popular, 1910.

RELATÓRIO apresentado ao Conselho municipal em 20 de setembro de 1911, pelo Intendente José Barboza Gonçalves. Pelotas: Of. do Diário Popular, 1911.

RELATÓRIO do Ginásio São José. Pelotas: Departamento Nacional de Ensino, 1944.

SERBIN, Kenneth P. Padres, celibato e conflito 
social: uma história da Igreja Católica no Brasil. São Paulo: Companhia das Letras, 2008.

SILVA, Tomaz Tadeu da. (Org.). O sujeito da educação: estudos foucaultianos. $5^{\circ}$ edição. Petrópolis: Editora Vozes, 2002.

TAMBARA, Elomar. Positivismo e Educação: a educação no Rio Grande do Sul sob o castilhismo. Pelotas: Ed. da Universidade, 1995.
O Estado, Igreja e Educação no Brasil do regalismo ao ultramontanismo (1870/1935). In: Linguagens, Educação e Sociedade. Teresina. Ano 11, nº 14. jan/jun. 2006. [24-36].

UMA RELIGIOSA de São José. Revivendo um longínquo passado. Resumo histórico da Congregação das Irmãos de São José (1648-1954). São Paulo: Editora Ave Maria, 1955.

\section{Sobre os autores:}

Eduardo Arriada: Doutor em Educação pela Pontifícia Universidade Católica do Rio Grande do Sul; Professor Adjunto II do Departamento de Fundamentos da Educação da Faculdade de Educação da Universidade Federal de Pelotas; Pesquisador do Centro de Estudos e Investigações em História da Educação - CEIHE-FaE/UFPEL.

E-mail: earriada@hotmail.com

Rita de Cássia Grecco dos Santos: Mestre e Doutoranda em Educação pela Universidade Federal de Pelotas; Professora Assistente IV do Instituto de Educação da Universidade Federal do Rio Grande; Pesquisadora do CEIHE-FaE/UFPEL e do Núcleo de Documentação da Cultura Afro-Brasileira - ATABAQUE/FURG.

E-mail: ritagrecco@yahoo.com 
